\title{
Blonanserin treatment in patients with methamphetamine-induced psychosis comorbid with intellectual disabilities
}

This article was published in the following Dove Press journal:

Neuropsychiatric Disease and Treatment

14 December 2016

Number of times this article has been viewed

\section{Kosuke Okazaki \\ Manabu Makinodan \\ Kazuhiko Yamamuro \\ Tomoyo Takata \\ Toshifumi Kishimoto}

Department of Psychiatry, Nara

Medical University School of

Medicine, Kashihara, Japan
Correspondence: Manabu Makinodan Department of Psychiatry, Nara Medical University School of Medicine, 840 Shijo-cho Kashihara, Nara 634-852I, Japan

Tel +8I 74422305 I

Fax +81744223854

Email mmm@naramed-u.ac.jp
Objective: Methamphetamine (MA) use has recently been associated with high levels of psychiatric hospitalization and serious social dysfunction. MA use causes frequent psychotic symptoms, which can be treated with antipsychotics. However, people with intellectual disabilities (ID) are vulnerable to adverse effects resulting from treatment with antipsychotic medications. Method: We report two cases of MA-induced psychosis (MAP) in patients with ID who were treated with the antipsychotic blonanserin.

Results: In both the cases presented, symptoms of psychosis were improved by switching medications from other antipsychotic drugs to blonanserin. Despite the presence of ID in these patients, no significant adverse effects, such as sedation, were detected after treatment with blonanserin.

Conclusion: Blonanserin may be an effective and well-tolerated pharmacotherapeutical treatment for patients with MAP comorbid with ID. However, further work is necessary to validate this claim.

Keywords: methamphetamine, methamphetamine-induced psychosis, intellectual disabilities, blonanserin

\section{Introduction}

Approximately 5\% of the adult population in the United States has used methamphetamine (MA) at least once, and there are approximately 35 million MA users worldwide, including in Japan. ${ }^{1,2}$ MA intake causes psychotic symptoms, such as paranoid delusions and hallucinations, in individuals without pre-existing psychotic manifestations. ${ }^{3,4}$ MA-induced psychosis (MAP) occurs in $10 \%$ to $60 \%$ of MA abusers. ${ }^{5}$ MAP is likely due to repeated administration or the use of high doses $^{6}$ in MA abusers who are especially vulnerable. It can have deleterious physical effects, including changes in brain volume, ${ }^{7,8}$ pulmonary hypertension, ${ }^{9}$ and kidney damage. ${ }^{10}$ MAP is associated with the long-term enhancement of dopamine release in the striatum and nucleus accumbens. Therefore, dopamine antagonists, including atypical antipsychotics, have potential for the treatment of patients with MAP. ${ }^{11}$

People with intellectual disabilities (ID) suffer disproportionately from substance abuse problems, including use of MA. ${ }^{12}$ The prevalence of use and misuse of several illicit drugs is relatively higher among people with ID than among people without ID. ${ }^{13}$ However, treatment of individuals with MAP comorbid with ID can be challenging since patients with ID are more likely to experience adverse effects, such as tardive dyskinesia, akathisia, weight gain, and sedation with antipsychotics treatment, ${ }^{14}$ which 
might be due to minute structural brain abnormalities. ${ }^{15}$ Blonanserin is an atypical antipsychotic drug that exhibits a high affinity for the dopamine $\mathrm{D}_{2} / \mathrm{D}_{3}$ and the serotonin $5-\mathrm{HT}_{2 \mathrm{~A}}$ receptors. ${ }^{16}$ Thus, blonanserin is efficacious in the treatment of positive and negative symptoms as well as cognitive impairments. ${ }^{17}$ Moreover, blonanserin is generally well tolerated and is less likely to elicit adverse effects such as body weight gain, hyperprolactinemia, and extrapyramidal symptoms. ${ }^{18,19}$ Antipsychotics with few adverse effects, such as blonanserin, ${ }^{20}$ are required for the treatment of patients with MAP comorbid with ID.

To the best of our knowledge, this is the first report to assess the use of blonanserin in the treatment of patients with MAP comorbid with ID. These two cases support the effectiveness of blonanserin as a viable alternative to antipsychotics for treating patients with MAP comorbid with ID.

\section{Case presentation Case A}

Patient A was a 25-year-old woman with mild ID (Full Intelligence Quotient [FIQ] =53). She had performed poorly in school from junior high school onwards and occasionally taken organic solvent. She started intermittently using MA at 15 years of age after graduating from junior high school. She began experiencing visual and auditory hallucinations at 19 years of age; at the age of 21 years, treatment began for her at a local clinic with atypical antipsychotics including aripiprazole (30 mg/day), olanzapine (10 mg/day), and paliperidone (6 mg/day) (drugs were administered nonconcurrently). Although she continued to take the medicines, adverse effects such as drowsiness, weight gain, and amenorrhea led her to keep complaining about the prescriptions. Eventually, every treatment failed to improve her symptoms despite good compliance to the treatment. The auditory hallucinations had a significant negative impact on her activities of daily living and social relationships, contributing to self-mutilation (cutting herself repeatedly) and an incident in which she ran away from home. She was referred to our hospital at 24 years of age.

Examinations including magnetic resonance imaging (MRI) indicated no brain abnormalities in Patient A. She was diagnosed with MAP in accordance with the Diagnostic and Statistical Manual of Mental Disorders, fifth edition (DSM-5). Symptoms of MAP were assessed using the Japanese version of the Positive and Negative Symptom Scale (PANSS), ${ }^{21}$ in which higher scores indicate greater severity according to a 7-point Likert scale. Subscale scores were calculated using small sets of variables based on the three domains of the PANSS: positive, negative, and general psychopathological symptoms. ${ }^{22}$ Patient A obtained a PANSS score of 156. She did not have schizophrenia or any other psychiatric disorders, and was thus prescribed $8 \mathrm{mg}$ of blonanserin, with the expectation that it would elicit the fewest adverse effects. Every 3 days, the dose was increased by $4 \mathrm{mg}$ until it reached $20 \mathrm{mg} /$ day. Over the course of 2 weeks, the patient showed improvements with respect to her positive symptoms, and she obtained a PANSS score of 87 . However, when the blonanserin dose was increased to $20 \mathrm{mg} /$ day, patient A developed akathisia and was thus prescribed clonazepam. Within several days, the symptoms of akathisia had nearly disappeared. Therefore, the dosage of blonanserin was increased to $24 \mathrm{mg} /$ day. After 1 month with a daily blonanserin dosage of $24 \mathrm{mg} /$ day with clonazepam, Patient A reported that her auditory hallucinations had nearly disappeared, with few adverse effects (PANSS score of 62). Patient A was able to continue taking blonanserin and clonazepam for at least 18 months (PANSS score of 39).

\section{Case B}

Patient B was a 24-year-old woman with mild ID (FIQ =63). She had repeated a year in high school because of poor academic performance and occasionally taken organic solvent. She started using MA around the age of 19 years. At the age of 22 years, she began to experience Capgras delusions and delusions of persecution. She visited the local clinic and was prescribed aripiprazole (12 mg/day). Owing to drowsiness, she discontinued therapy. At the age of 24 years, the Capgras delusions and delusions of persecution resulted in patient $B$ dispersing burning oil and brandishing a kitchen knife and golf club with the intention of harming her family, after which she was admitted to our hospital. MRI revealed no signs of brain abnormality in Patient B. She was diagnosed with MAP in accordance with the DSM-5 and her PANSS score, which was 144. Patient B did not have schizophrenia or any other psychiatric disorders. Blonanserin was prescribed with the expectation that it would lead to a few adverse effects; dosing was progressively increased to $12 \mathrm{mg} /$ day. After 2 weeks at $12 \mathrm{mg} /$ day, psychomotor excitation had improved and Capgras delusions had subsided (PANSS score of 88). Subsequently, the dosage of blonanserin was increased to $16 \mathrm{mg} /$ day; however, this led to extrapyramidal symptoms. Therefore, patient B was concomitantly prescribed biperiden. Patient B was discharged from the hospital 2 weeks after treatment because her symptoms improved substantially, with a few adverse effects (PANSS score of 74) as a result of concomitant blonanserin and biperiden therapy. 
Patient B was able to continue taking blonanserin and biperiden for at least 12 months (PANSS score of 43).

\section{Discussion}

To the best of our knowledge, the cases presented here represent the original evidence of prolonged and well-tolerated blonanserin therapy, leading to a reduction in positive symptoms in patients with MAP comorbid with ID.

In many studies, atypical antipsychotics such as risperidone, ${ }^{23}$ olanzapine, ${ }^{24}$ quetiapine, ${ }^{25}$ and aripiprazole ${ }^{26}$ have been prescribed to treat patients with MAP. However, a few studies have shown reliable effects of antipsychotics in treating MAP, and no significant differences in clinical efficacy among antipsychotics have been reported in MAP patients. ${ }^{27}$ Treatment of patients with MAP comorbid with ID can be particularly challenging because of increased vulnerability to adverse effects from any antipsychotic drugs. ${ }^{14}$ Although the detailed mechanisms contributing to the vulnerability in people with ID are unknown, these patients are unable to discontinue neuroleptic treatment. ${ }^{28}$ Whereas brain abnormalities that might induce drug vulnerability were not detected by MRI in the two cases, both patients somehow experienced several adverse effects with antipsychotics treatment as expected. Consequently, it is necessary to select appropriate antipsychotics for patients with MAP and comorbid ID, considering the benefits of pharmaceutical treatment in this population. Blonanserin was prescribed to the patients with the expectation that it would be well tolerated and elicit fewer adverse effects, resulting in the rapid amelioration of symptoms.

Previous research suggests that people with ID suffer disproportionately from substance abuse problems. This may be due to a lack of empirical evidence to inform prevention and treatment efforts. ${ }^{12}$ As mentioned, people with ID are particularly susceptible to the adverse effects of antipsychotics because their brain structure differs from that of the general population. Therefore, it is important to choose antipsychotics with fewer adverse effects and high efficacy. Blonanserin is considered to be an effective and generally well-tolerated option for the treatment of schizophrenia. ${ }^{20}$

Blonanserin is a second-generation antipsychotic that possesses unique features compared with other antipsychotics. It has dopamine $\mathrm{D}_{2}$ receptor, dopamine $\mathrm{D}_{3}$ receptor, and serotonin $5-\mathrm{HT}_{2 \mathrm{~A}}$ receptor blocking activity. While it blocks dopamine $\mathrm{D}_{2}$ receptors, thus improving positive symptoms, ${ }^{29}$ blonanserin has weak dopamine $\mathrm{D}_{1}$ receptor and adrenergic alpha $\mathrm{f}_{1}$ receptor blocking activity and is almost completely devoid of histamine $\mathrm{H}_{1}$ and muscarinic $\mathrm{M}_{1}$ antagonist activity. ${ }^{17}$ Thus, it elicits a few adverse effects when used to treat psychosis, even in patients with ID. Previous studies have suggested that dopamine $\mathrm{D}_{3}$ receptor activity can influence cognitive function by modulating the medial prefrontal cortex, despite the relatively small number of dopamine $\mathrm{D}_{3}$ receptors in this region. ${ }^{18,30}$ Together with our results, these data suggest that blonanserin is an effective and well-tolerated treatment, even in patients with MAP comorbid with ID. Indeed, blonanserin might represent a better option compared with other traditional antipsychotic agents, as it appears to lead to fewer adverse effects.

As this report involves only two cases, a major limitation of our study is the small sample size. Another limitation is that the use of organic solvent might affect their intelligence. Future studies should continue to assess the effectiveness of blonanserin in treating patients with MAP comorbid with ID.

\section{Conclusion}

These two cases indicate that blonanserin might function as an efficacious and well-tolerated therapy in the treatment of patients with MAP and comorbid ID. Further studies with larger sample sizes are needed to validate the efficacy, safety, and tolerability of blonanserin in the treatment of patients with MAP comorbid with ID.

\section{Acknowledgments}

We would like to thank the patients and their families for their cooperation. As we encountered these cases during regular clinical practice, the need for ethics approval and consent was waived. We obtained written informed consent for the publication of this case report from the patients. Data sharing was not applicable to this article as no datasets were generated or analyzed during the current study.

\section{Author contributions}

$\mathrm{KO}$ and TT were involved in the collection of the data and wrote the first draft of the manuscript. KY, MM, and TK supervised the entire project, were critically involved in the design, and contributed to the editing of the final manuscript. All authors contributed toward data analysis, drafting and revising the paper and agree to be accountable for all aspects of the work.

\section{Disclosure}

The authors have no competing interests to declare that are relevant to the content of this submission. 


\section{References}

1. Roehr B. Half a million Americans use methamphetamine every week. BMJ. 2005;331:476.

2. Naruse N. Methamphetamine, cannabis. Nihon Rinsho. 2015;73: 1481-1486.

3. Kishimoto M, Ujike H, Motohashi Y, et al. The dysbindin gene (DTNBP1) is associated with methamphetamine psychosis. Biol Psychiatry. 2008;63:191-196.

4. Matsuzawa D, Hashimoto K, Miyatake R, et al. Identification of functional polymorphisms in the promoter region of the human PICK1 gene and their association with methamphetamine psychosis. Am J Psychiatry. 2007;164:1105-1114.

5. Mahoney JJ 3rd, Kalechstein AD, De La Garza R 2nd, Newton TF. Presence and persistence of psychotic symptoms in cocaine- versus methamphetamine-dependent participants. Am J Addict. 2008;17: $83-98$.

6. Batki SL, Harris DS. Quantitative drug levels in stimulant psychosis: relationship to symptom severity, catecholamines and hyperkinesia. Am J Addict. 2004;13:461-470.

7. Morales AM, Lee B, Hellemann G, O'Neill J, London ED. Graymatter volume in methamphetamine dependence: cigarette smoking and changes with abstinence from methamphetamine. Drug Alcohol Depend. 2012;125:230-238.

8. London ED, Kohno M, Morales AM, Ballard ME. Chronic methamphetamine abuse and corticostriatal deficits revealed by neuroimaging. Brain Res. 2015;1628:174-185.

9. Chin KM, Channick RN, Rubin LJ. Is methamphetamine use associated with idiopathic pulmonary arterial hypertension? Chest. 2006;13: $1657-1663$.

10. Ishigami A, Tokunaga I, Gotohda T, Kubo S. Immunohistochemical study of myoglobin and oxidative injury-related markers in the kidney of methamphetamine abusers. Leg Med (Tokyo). 2003;5:42-48.

11. Sato M, Numachi Y, Hamamura T. Relapse of paranoid psychotic state in methamphetamine model of schizophrenia. Schizophr Bull. 1992; 18:115-122.

12. Slayter EM. Understanding and overcoming barriers to substance abuse treatment access for people with mental retardation. JSoc Work Disabil Rehabil. 2008;7:63-80.

13. VanDErNagel J, Kiewik M, Buitellar J, DeJong C. Staff perspectives of substance use and misuse among adults with intellectual disabilities enrolled in Dutch disability services. $J$ Policy Pract Intellect Disabil. 2011;8:143-149.

14. Matson JL, Mahan S. Antipsychotic drug side effects for persons with intellectual disability. Res Dev Disabil. 2010;31:1570-1576.

15. Polednak AP. Post-mortem neuropathology in a mentally retarded population. Lancet. 1977;1:492-493.
16. Murasaki M, Nishikawa $\mathrm{H}$, Ishibashi T. Dopamine-serotonin antagonist: receptor binding profile of a novel antipsychotic blonanserin. Jpn JClin Psychopharmacol. 2008;11:845-854.

17. Tenjin T, Miyamoto S, Ninomiya Y, et al. Profile of blonanserin for the treatment of schizophrenia. Neuropsychiatr Dis Treat. 2013;9: $587-594$.

18. Hida H, Mouri A, Mori K, et al. Blonanserin ameliorates phencyclidineinduced visual-recognition memory deficits: the complex mechanism of blonanserin action involving $\mathrm{D}_{3}-5-\mathrm{HT}_{2 \mathrm{~A}}$ and $\mathrm{D}_{1}$-NMDA receptors in the mPFC. Neuropsychopharmacology. 2015;40:601-613.

19. Garcia E, Robert M, Peris F, Nakamura H, Sato N, Terazawa Y. The efficacy and safety of blonanserin compared with haloperidol in acutephase schizophrenia: a randomized, double-blind, placebo-controlled, multicentre study. CNS Drugs. 2009;23:615-625.

20. Deeks ED, Keating GM. Blonanserin: a review of its use in the management of schizophrenia. CNS Drugs. 2010;24:65-84.

21. Kay SR, Fiszbein A, Opler LA. The positive and negative syndrome scale (PANSS) for schizophrenia. Schizophr Bull. 1987;13:261-276.

22. Sawamura J, Morishita S, Ishigooka J. Is there a linear relationship between the Brief Psychiatric Rating Scale and the Clinical Global Impression-Schizophrenia scale? A retrospective analysis. BMC Psychiatry. 2010;10:105.

23. Misra L, Kofoed L. Risperidone treatment of methamphetamine psychosis. Am J Psychiatry. 1997;154:1170.

24. Shoptaw SJ, Kao U, Ling WW. Treatment for amphetamine psychosis. Cochrane Database Syst Rev. 2008:Cd003026.

25. Verachai V, Rukngan W, Chawanakrasaesin K, et al. Treatment of methamphetamine-induced psychosis: a double-blind randomized controlled trial comparing haloperidol and quetiapine. Psychopharmacology (Berl). 2014;231:3099-3108.

26. Sulaiman AH, Gill JS, Said MA, Zainal NZ, Hussein HM, Guan NC. A randomized, placebo-controlled trial of aripiprazole for the treatment of methamphetamine dependence and associated psychosis. Int J Psychiatry Clin Pract. 2013;17:131-138.

27. Leelahanaj T, Kongsakon R, Netrakom P. A 4-week, double-blind comparison of olanzapine with haloperidol in the treatment of amphetamine psychosis. J Med Assoc Thai. 2005;88 Suppl 3:S43-S52.

28. Pary RJ. Discontinuation of neuroleptics in community-dwelling individuals with mental retardation and mental illness. Am J Ment Retard. 1995;100:207-212.

29. Stahl SM. Stahl's Essential Psychopharmacology: Neuroscientific Basis and Practical Application. 3rd ed. Cambridge: Cambrige University Press; 2008

30. Nakajima S, Gerretsen P, Takeuchi H, et al. The potential role of dopamine $\mathrm{D}_{3}$ receptor neurotransmission in cognition. Eur Neuropsychopharmacol. 2013;23:799-813.
Neuropsychiatric Disease and Treatment

\section{Publish your work in this journal}

Neuropsychiatric Disease and Treatment is an international, peerreviewed journal of clinical therapeutics and pharmacology focusing on concise rapid reporting of clinical or pre-clinical studies on a range of neuropsychiatric and neurological disorders. This journal is indexed on PubMed Central, the 'PsycINFO' database and CAS,
Dovepress

and is the official journal of The International Neuropsychiatric Association (INA). The manuscript management system is completely online and includes a very quick and fair peer-review system, which is all easy to use. Visit http://www.dovepress.com/testimonials.php to read real quotes from published authors. 